\title{
SIPGANG: Sistem Pendukung Keputusan Rekomendasi Magang Industri Berbasis Multi Attribute Utility Theory (MAUT)
}

\author{
Ratih Hafsarah Maharrani" ${ }^{\# 1}$, Abdul Rohman Supriyono ${ }^{\# 2}$, Lutfi Syafirullah ${ }^{\# 3}$ \\ ${ }^{\#}$ Jurusan Teknik Informatika Politeknik Negeri Cilacap \\ Jl. Dr. Soetomo No. 1 Sidakaya Cilacap Jawa Tengah 53212 \\ ${ }^{1}$ ratih.hafsarah@pnc.ac.id \\ 2a.rohman.sy@pnc.ac.id \\ ${ }^{3}$ syafirullah.lutfiegmail.com
}

\begin{abstract}
Abstrak - Magang adalah proses penerapan bidang keilmuan dan keterampilan yang diperoleh di kampus pada dunia industry. Dalam pelaksanaannya, saat mahasiswa selesai melaksanakan magang ada beberapa mengeluhkan bahwa perusahaan tempat magang tidak sesuai dengan standar yang diinginkan, tidak sesuai bidang serta beban kerja yang berlebih sehingga dalam pelaksanaanya mahasiswa merasa tidak bisa optimal dalam menggunakan kemampuan yang dimiliki. Hal ini dikarenakan adanya subjektifitas dalam penentuan tempat magang, mahasiswa memilih sendiri tempat magang tersebut yang terkadang belum mengetahui job desk yang akan dikerjakan. Selain itu koordinator magang jurusan merekomendasikan tempat magang berdasarkan penilaian pembimbing magang saat visitasi padahal tidak mengetahui keadaan sebenarnya yang telah terlaksana. Sehingga dalam hal ini dibutuhkan adanya sebuah sistem yang mampu membantu dalam pengambilan keputusan rekomendasi tempat magang. Penelitian ini dibuat dengan menerapkan metode pengembangan system Rapid Development Prototyping (RAD) dan penilaian rekomendasi diperoleh menggunakan metode MAUT (Multi Attribute Utility Theory). Metode MAUT akan mengolah penilaian dari masing kriteria (jam kerja, bobot tugas yang diberikan selama magang, kesesuaian tugas dengan keahlian, standar perusahaan, penerapan K3 di perusahaan, fasilitas dan peralatan praktik untuk peserta magang serta bidang keahlian) sesuai dengan bobot yang ditentukan dengan tujuan memberikan penilaian dari sisi mahasiswa yang telah selesai pelaksanaan magang terhadap industri bersangkutan. Pengujian pada aplikasi SIPGANG penentuan rekomendasi industry menggunakan uji kuisioner dengan Sistem Usability Scale (SUS) dan didapatkan hasil akhir 72 yang menyatakan bahwa system dalam kategori layak untuk digunakan.
\end{abstract}

Kata kunci - SPK, Rekomendasi Magang, Metode Multi Atribute Utility Theory

\section{PEndahuluan}

Ketenagakerjaan, pemagangan adalah bagian dari system pelatihan kerja yang diselenggarakan secara terpadu antara pelatihan di lembaga pelatihan dengan bekerja secara langsung melalui bimbingan dan pengawasan oleh instruktur atau pekerja yang lebih berpengalaman dalam proses produksi barang dan/atau jasa di perusahaan dalam rangka penguasaan keterampilan atau keahlian tertentu [1]. Setiap peserta didik harus merasakan pengalaman bekerja pada industri agar menguasai keterampilan atau keahlian kerja.

Pelaksanaan program magang adalah sebagai upaya untuk menjembatani keseimbangan antara ketrampilan dan pengetahuan yang diperoleh mahasiswa pada dunia industri [2]. Melalui program magang inilah kompetensi life skill didapatkan sebagai aktualisasi teori yang dimaksudkan agar terjadi relevansi antara perguruan tinggi dengan dunia industri [3]. Proses magang dimulai dengan mahasiswa menentukan industri untuk pelaksanaan magang, ada yang mencari sendiri industri tersebut namun ada pula yang berdasarkan rekomendasi koordinator magang jurusan. Mahasiswa yang bersangkutan belum mengetahui betul mengenai industri yang akan dijadikan subjek magang sehingga perusahaan yang dipilih tidak sesuai standar yang diinginkan. Selain itu dalam pelaksanaannya, kegiatan magang yang dilaksanakan tidak berjalan sebagaimana mestinya sebab mahasiswa hanya sekedar menyelesaikan kegiatan magang tetapi tidak dapat menerapkan kompetensi dan tidak maksimal dalam melakukan pekerjaan karena tidak sesuai dengan bidang yang dimiliki [4]. Hal lain yang menjadi permasalahan yakni dalam prakteknya di industri, tingkat kepercayaan dalam pemberian pekerjaan dari pihak perusahaan atau pembimbing lapangan terhadap mahasiswa magang masih rendah. Bagi perusahaan yang bersangkutan, mahasiswa magang dianggap masih "belajar". Sehingga ketika melakukan pekerjaan dan terdapat kesalahan, mahasiswa dianggap menghambat pekerjaan. Permasalahan lainnya yakni beban kerja, mahasiswa dituntut untuk lebih aktif dan kreatif dalam menangani pekerjaan padahal mahasiswa tidak berani dalam melaksanakan pekerjaan sebelum adanya perintah yang jelas dikarenakan pembimbing 
lapangan memiliki beberapa pekerjaan lain sehingga kurang optimal dalam pemberian arahan mengenai tugas yang harus dilakukan.

Memperhatikan masalah yang terjadi, perlu adanya sebuah sistem yang digunakan sebagai alat bantu pengambilan keputusan rekomendasi kepada mahasiswa dan koordinator magang jurusan mengenai perusahaan tempat magang. Pengembangan sistem dengan menerapkan metode MAUT dimana metode ini digunakan pada kasus yang memiliki beberapa kepentingan yang nilainya diubah ke nilai numerik dengan skala $0-1$ dan hasil akhir yang didapatkan berupa urutan peringkat evaluasi [5].

Penelitian terdahulu yang pernah dilakukan diantaranya metode Weight Product dalam pembuatan sistem rekomendasi penempatan kerja industry pada SMK Muhammadiyah 01 Pekanbaru [6]. Terdapat 5 kriteria yakni jarak, siswa yang dibutuhkan, jam kerja, beban kerja dan waktu tempuh ke lokasi. Hasil akhir penelitian diperoleh bahwa dengan metode WP (Weight Product) membantu user dalam memberikan rekomendasi pada siswa untuk menentukan lokasi prakerin sesuai kebutuhan dan kriteria yang ditetapkan. Namun terdapat kelemahan dalam penelitian ini yakni dalam penentuan rekomendasi yang dihasilkan, penilaian hanya menghasilkan nilai terbesar yang terpilih sebagai alternatif terbaik. Penelitian lainnya yakni system pengelolaan magang pada SMKN Bantarkalong. Metode DIA (The Distance To The Ideal Alternative) digunakan sebagai alternatif perhitungan rekomendasi tempat prakerin [7]. Penelitian ini menggunakan 5 kriteria yang berasal dari nilai siswa untuk proses perhitungan, yakni: nilai jaringan nirkable, nilai troubleshooting, nilai admin server, nilai perakitan komputer dan nilai sistem komputer. Data kriteria dalam penelitian ini sifatnya dinamis, sehingga apabila sewaktuwaktu ada perubahan data maka sistem tetap dapat digunakan namun untuk perhitungan bobot tempat prakerin masih belum otomatis sehingga perlu menyimpan data satu persatu. Selain itu, penelitian lain telah dilakukan pula mengenai rekomendasi tempat kerja praktek bagi mahasiswa Fte Universitas Telkom dengan Metode Naïve Bayes [8]. Dalam penelitian ini membuat website sistem pendukung keputusan yang digunakan untuk memberikan rekomendasi perusahaan sesuai dengan kebutuhan mahasiswa. Dari penelitian didapat rekomendasi dengan akurasi sebesar $37 \%$, precision $47 \%$, recall sebesar $57 \%$, dan FI-score sebesar 47\%. Dari data tersebut dapat terlihat bahwa Nä̈ve Bayes dalam klasifikasi belum optimal karena hanya menghasilkan akurasi sebesar $37 \%$.

Adapun tujuan dari penelitian ini adalah menerapkan metode MAUT dalam sistem pendukung keputusan untuk memperoleh rekomendasi tempat magang industri apakah perusahaan yang bersangkutan layak untuk di rekomendasikan kembali pada tahun berikutnya atau tidak. Dalam penelitian ini dibatasi hanya menggunakan 7 nilai kriteria, yang merupakan hasil penilaian mahasiswa yang telah melaksanakan magang untuk membantu dalam pengambilan keputusan, dan sistem akan menampilkan rekomendasi berupa hasil perangkingan dengan memberikan range pada hasil penilaian sehingga dapat terlihat apakah tempat magang tersebut direkomendasikan, atau tidak bagi koordinator jurusan dan mahasiswa periode berikutnya.

\section{TAHAPAN PENELITIAN}

Tahapan dalam penelitian ini menerapkan metode pengembangan sistem yakni Rapid Applications Development Prototyping (RAD). Metode RAD adalah metode pengembangan yang dikatakan sangat menghemat waktu karena relative singkat. Implementasi metode ini dengan mementingkan user / pengguna dalam pengambil keputusan di setiap tahapan pengembangan [9]. Gambar berikut menjelaskan penerapan tahapan-tahapan metode RAD dalam pembuatan sistem [10] :

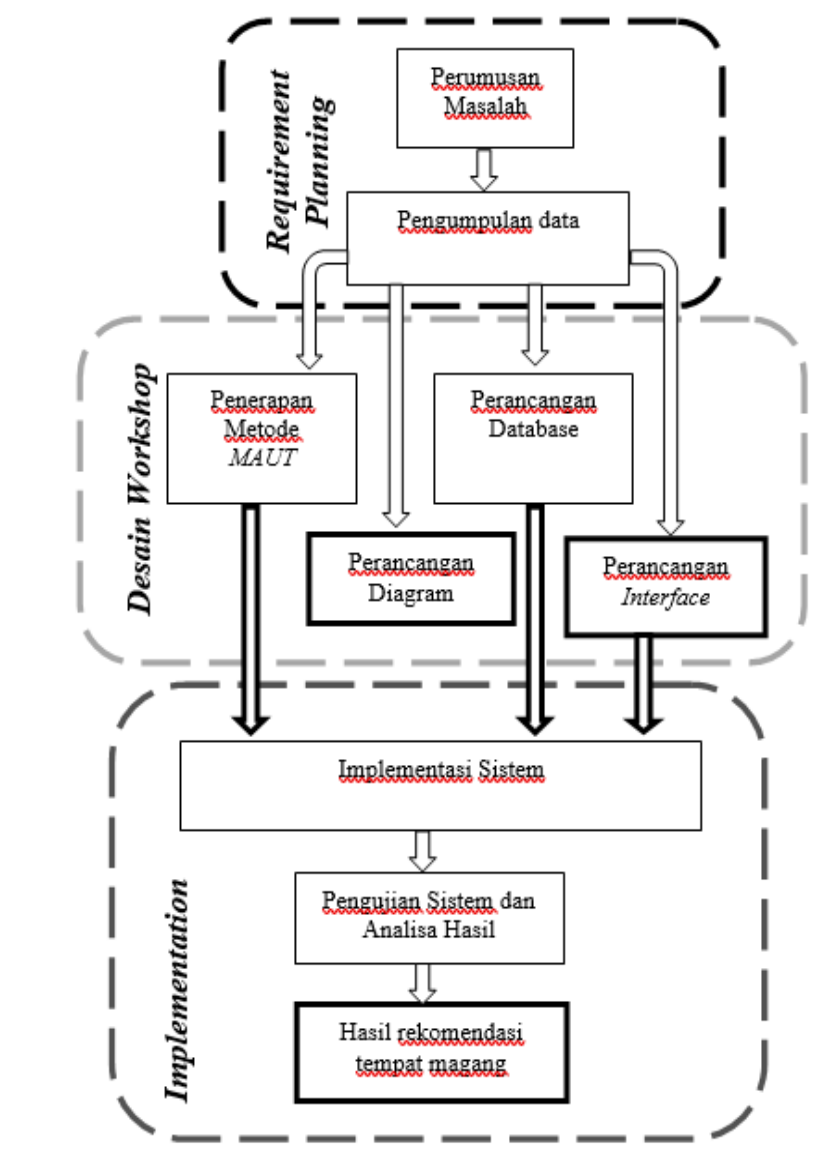

Gambar. 1 Tahapan penelitian yang akan dilakukan dengan metode pengembangan sistem RAD

Tahap pengembangan sistem dimulai dari tahap rencana kebutuhan (Requirement Planning) dengan menentukan kebutuhan sistem yakni identifikasi kebutuhan data, informasi, kendala dan alternatif pemecahan masalah yang ada.

Tahapan selanjutnya adalah Desain Workshop yakni merancang desain terhadap sistem yang akan dibangun agar didapatkan penyelesaian masalah dengan pemilihan alternatif terbaik [11]. Pada fase ini akan merancang diagram, database dan tampilan antar muka (mockup) dari system yang sedang dibangun. 
TABEL I

CONTOH DATA YANG DIGUNAKAN DALAM PERHITUNGAN

\begin{tabular}{|c|c|c|c|c|c|c|c|c|c|}
\hline No & Industri & Nama & $\begin{array}{l}\text { Jam } \\
\text { Kerja }\end{array}$ & $\begin{array}{l}\text { Bobot } \\
\text { Tugas }\end{array}$ & $\begin{array}{l}\text { Kesesuaian } \\
\text { Tugas }\end{array}$ & $\begin{array}{l}\text { Standar } \\
\text { Perusahaan }\end{array}$ & $\begin{array}{c}\text { Kriteria } \\
\text { K3 }\end{array}$ & $\begin{array}{c}\text { Fasilitas } \\
\text { dan } \\
\text { Peralatan } \\
\text { Praktik }\end{array}$ & $\begin{array}{c}\text { Bidang } \\
\text { Keahlian }\end{array}$ \\
\hline 1 & $\begin{array}{l}\text { Politeknik Negeri } \\
\text { Cilacap }\end{array}$ & $\begin{array}{l}\text { Adi Khoiron } \\
\text { Hasan }\end{array}$ & 4 & 3 & 4 & 4 & 3 & 4 & 4 \\
\hline 2 & $\begin{array}{l}\text { Politeknik Negeri } \\
\text { Cilacap }\end{array}$ & $\begin{array}{l}\text { Aimatuz } \\
\text { Zakiyah }\end{array}$ & 3 & 3 & 3 & 4 & 3 & 4 & 4 \\
\hline 3 & $\begin{array}{l}\text { Kejaksaan Negeri } \\
\text { Cilacap }\end{array}$ & $\begin{array}{l}\text { Alina Mei } \\
\text { Cahyaningtyas }\end{array}$ & 3 & 4 & 3 & 4 & 4 & 3 & 4 \\
\hline 4 & Dinas KBPPPA & $\begin{array}{l}\text { Amalia Putri } \\
\text { Utami }\end{array}$ & 3 & 3 & 3 & 3 & 4 & 3 & 3 \\
\hline 5 & $\begin{array}{l}\text { Politeknik Negeri } \\
\text { Cilacap }\end{array}$ & $\begin{array}{l}\text { Amirrul } \\
\text { Muwafaq }\end{array}$ & 3 & 3 & 3 & 3 & 4 & 3 & 3 \\
\hline .. & $\cdots$ & $\cdots$ & $\cdots$ & $\cdots$ & $\cdots$ & $\cdots$ & $\cdots$ & $\cdots$ & $\cdots$ \\
\hline$x_{47}$ & $\begin{array}{l}\cdots \\
\text { Bappeda }\end{array}$ & $\begin{array}{l}\text { Yolland } \\
\text { Waynara }\end{array}$ & $\begin{array}{l}\cdots \\
3\end{array}$ & $\begin{array}{l}\cdots \\
4\end{array}$ & $\begin{array}{l}\cdots \\
3\end{array}$ & $\begin{array}{l}\cdots \\
3\end{array}$ & $\begin{array}{l}\cdots \\
4\end{array}$ & $\begin{array}{l}\cdots \\
3\end{array}$ & $\begin{array}{l}\cdots \\
3\end{array}$ \\
\hline 48 & $\begin{array}{l}\text { Kejaksaan Negeri } \\
\text { Cilacap }\end{array}$ & $\begin{array}{l}\text { Yossy } \\
\text { Yuliyatin }\end{array}$ & 3 & 3 & 4 & 4 & 2 & 3 & 4 \\
\hline
\end{tabular}

Selain itu dalam tahap Desain Workshop akan diterapkan perhitungan dengan metode MAUT dalam sistem untuk menghasilkan rekomendasi tempat magang. Metode MAUT merupakan skema evaluasi total $V(x)$ yang berasal dari suatu objek x yang digunakan untuk menilai produk dan memiliki banyak atribut penilaian sebagai bobot yang dijumlahkan dengan suatu nilai yang relevan terhadap dimensinya [12]. Utility adalah sebutan untuk ungkapan yang biasa digunakan [13]. MAUT menyajikan cara perbandingan kuantitatif yang umumnya mengkombinasikan pengukuran atas resiko dan keuntungan yang berbeda [14]. Solusi mampu diberikan oleh kriteria yang ada dengan beberapa alternatif [15]. Nilai numerik skala 0-1 dengan 0 adalah opsi terburuk serta 1 terbaik diubah dengan menggunakan metode MAUT dari beberapa kepentingan yang ada. Ini membolehkan perbandingan langsung yang bermacam ukuran [16]. Persamaan yang dapat mendefinisikan nilai perhitungan penilaian secara keseluruhan dapat dilihat dibawah ini :

$$
V(x)=\sum_{i=1}^{n} W j \cdot x i j
$$

Dimana :

$$
\begin{array}{ll}
\mathrm{V}(\mathrm{x}) & =\text { Penilaian total alternatif ke-x } \\
\mathrm{Wj} & =\begin{array}{l}
\text { Bobot yang menentukan nilai dari seberapa } \\
\text { penting elemen ke i terhadap elemen lain }
\end{array} \\
\mathrm{xij} & =\text { Nilai evaluasi dari sebuah objek ke } \mathrm{i} \\
\mathrm{i} & =\text { Indeks yang menunjukkan kriteria } \\
\mathrm{n} & =\text { Jumlah banyaknya kriteria }
\end{array}
$$

$\mathrm{U}(\mathrm{x})$ adalah fungsi utilitas untuk normalisasi setiap atribut $\mathrm{V}(\mathrm{x})$ menjadi skala $0-1$ sesuai dengan rumus:

$$
U(x)=\frac{\mathrm{x}-\mathrm{xi} \mathbf{i}^{-}}{x i^{+}+x i^{-}}
$$

Keterangani :

$\mathrm{U}(\mathrm{x})=$ Normalisasi bobot alternatif $\mathrm{x}$

$\mathrm{xi}=$ Bobot alternatif

$x i^{-}=$Bobot minimum dari kriteria ke-x

$x i^{+}=$bobot maksimum dari kriteria ke- $\mathrm{x}$

Tahapan terakhir dalam RAD adalah implementation yang memperlihatkan kepada user bahwa sistem telah siap untuk dioperasikan. Pada fase ini akan menampilkan beberapa output dari rancangan interface yang berupa tampilan aplikasi. Selain itu dilakukan pengujian system dengan System Usability Scale (SUS) yang bertujuan apakah aplikasi yang dibangun dapat berjalan dengan baik atau tidak.

\section{HASIL DAN PEMBAHASAN}

\section{A. Requirement Planning}

Dataset yang digunakan dalam penelitian merupakan data mahasiswa magang angkatan 2019 terdiri dari 48 data penilaian mahasiswa yang telah melaksanakan magang di 13 perusahaan (sebagai data alternatif). Adapun data yang digunakan seperti pada Tabel 1.

\section{B. Rancangan Design Sistem}

Dari data yang diperoleh dalam tahapan pengembangan sistem pendukung keputusan rekomendasi magang industri, selanjutnya akan dibuat design usecase, design awal rancangan pada aplikasi serta perancangan basis data.

Aplikasi pengelolaan magang yang dikembangkan dimulai dari proses pengajuan, bimbingan, penilaian seminar magang serta penilaian rekomendasi. Proses rekomendasi dengan perhitungan metode MAUT itu sendiri akan dapat diproses apabila magang telah terlaksana oleh mahasiswa. 


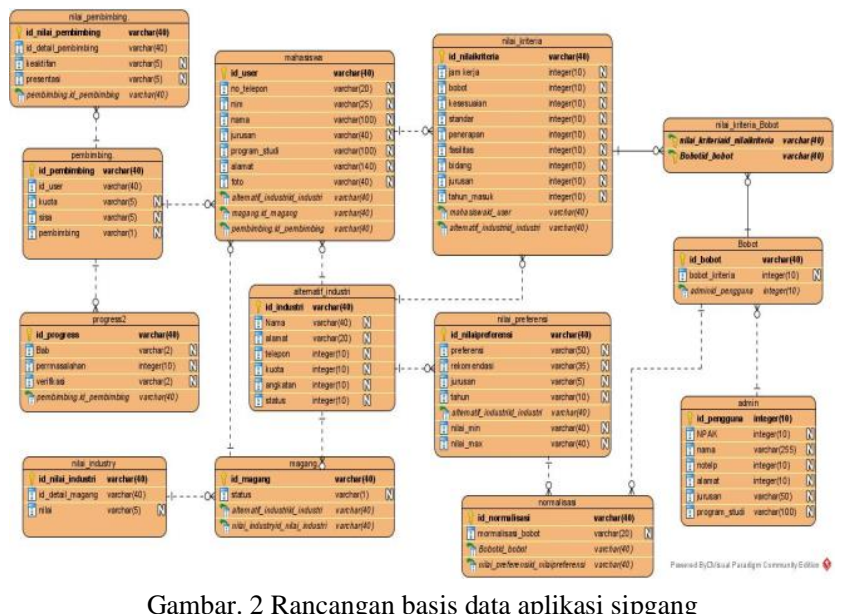

Dan setelah selesai pelaksanaan maka mahasiswa diminta untuk menilai industry tempat magang masingmasing sebagai rekomendasi industry tahun sebelumnya. Gambaran dari usecase diagram dapat dilihat pada Gambar 3.

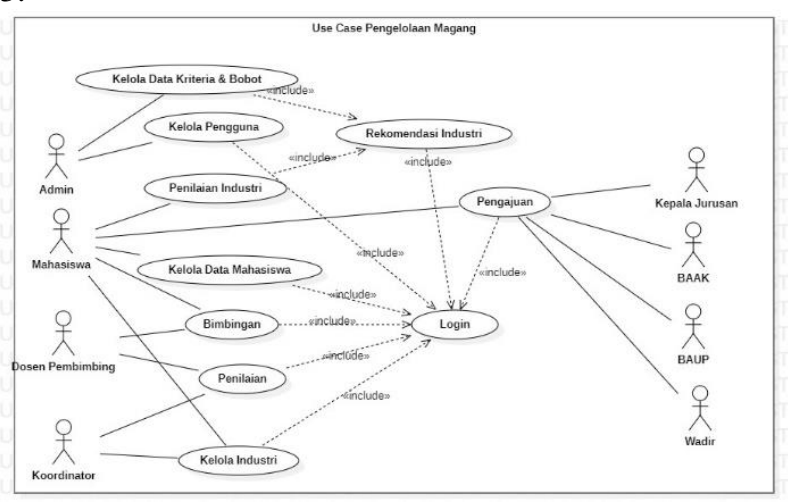

Gambar. 3 Usecase diagram rekomendasi magang

Pada perancangan Sistem Pendukung Keputusan rekomendasi magang dengan metode MAUT ini dapat diperlihatkan dalam bentuk conceptual skema ke model sesuai DBMS yang digunakan dan ditunjukkan pada gambar 2.

Sedangkan untuk rancangan input terdiri dari beberapa proses. Adapun beberapa rancangan mockup (desain interface) aplikasi dikembangkan yang berkaitan dengan SPK MAUT seperti input kriteria, input penilaian pada industri, hitung nilai normalisasi dapat dilihat pada Gambar 4, 5 dan 6.

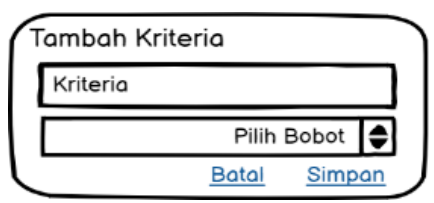

Gambar. 4 Inputan kriteria

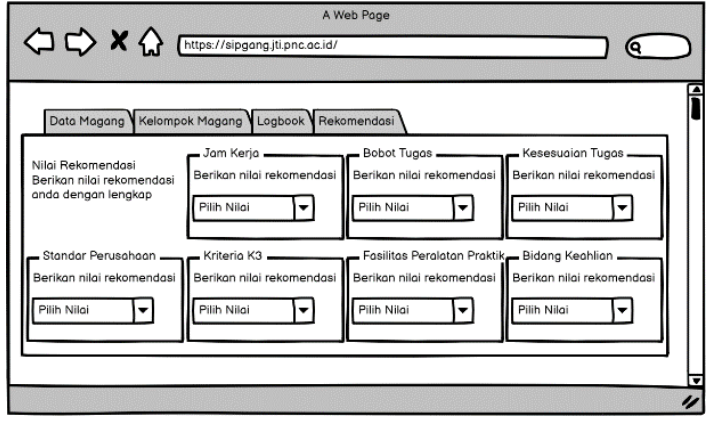

Gambar. 5 Inputan penilaian kriteria pada industri

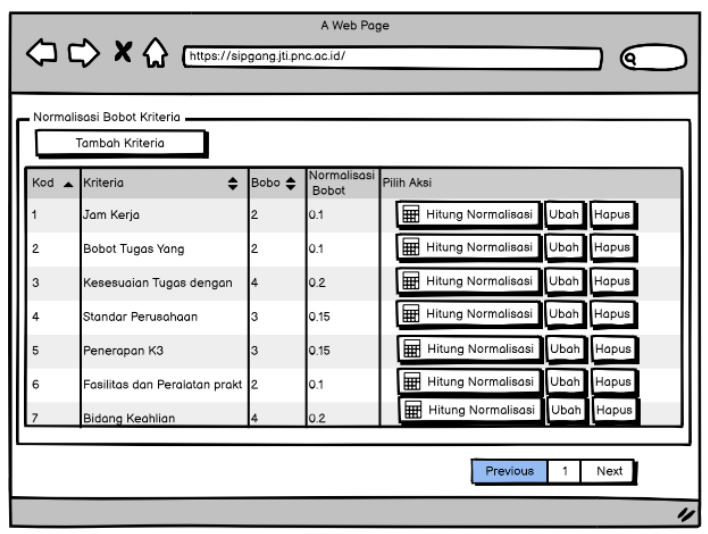

Gambar. 6 Mockup halaman normalisasi bobot

1) Alternatif, Kriteria dan Bobot Kriteria: Data alternatif diambil dari 13 data industri yang telah selesai dalam pelaksanaan magang seperti terlihat pada tabel II:

TABEL II

DATA ALTERNATIF

\begin{tabular}{|l|l|c|}
\hline No & Nama Industri & $\begin{array}{c}\text { Kode } \\
\text { Alternatif }\end{array}$ \\
\hline 1 & $\begin{array}{l}\text { Badan Pertanahan Nasional (BPN) } \\
\text { Kabupaten Cilacap }\end{array}$ & A1 \\
\hline 2 & Badan Pusat Statistik Cilacap & A2 \\
\hline 3 & Bappeda & A3 \\
\hline 4 & BPJS Ketenagakerjaan Cilacap & A4 \\
\hline 5 & Dinas KBPPPA & A5 \\
\hline 6 & Dinas Perikanan & A6 \\
\hline 7 & $\begin{array}{l}\text { InnoCircle Initiative, Inkubator Startup } \\
\text { Coop Indonesia }\end{array}$ & A8 \\
\hline 8 & Kejaksaan Negeri Cilacap & A9 \\
\hline 9 & Noviand Collection & A10 \\
\hline 10 & Politeknik Negeri Cilacap & A11 \\
\hline 11 & PT Telkom Akses Pugeran & A13 \\
\hline 12 & Sekretariat Daerah Kabupaten Cilacap & \\
\hline 13 & Stasiun Karantina Pertanian Kelas I Cilacap & \\
\hline
\end{tabular}

Data alternatif tersebut akan dinilai oleh masing-masing mahasiswa yang telah melaksanakan magang dengan dengan range penilaian 4 : sangat sesuai, 3 : sesuai, 2 : kurang sesuai, dan 1 : tidak sesuai. Pemilihan kriteria diperoleh berdasarkan informasi dari koordinator masingmasing jurusan, dimana kriteria tersebut sebagai acuan penilaian rekomendasi industri yang diberikan oleh dosen pembimbing saat melakukan visitasi. Namun karena seringkali terjadi ketidakkonsistenan hasil rekomendasi koordinator yang didapat dari hasil visitasi, maka penilaian 
yang dilakukan pada sistem rekomendasi magang berasal dari mahasiswa yang telah melaksanakan magang dengan range penilaian 4 : sangat sesuai, 3 : sesuai, 2 : kurang sesuai, dan 1 : tidak sesuai. Kriteria yang ditetapkan dalam perhitungan diantaranya :

1. $\mathrm{C} 1=$ Jam kerja : penilaian untuk jam masuk kerja dalam industri, normalnya adalah $8-10$ jam

2. $\mathrm{C} 2=$ Bobot Tugas: didasarkan pada penilaian mahasiswa terhadap beban tugas yang diberikan selama magang

3. $\mathrm{C} 3=$ Kesesuaian tugas dengan keahlian: didasarkan pada pengamatan atas kesesuaian tugas yang diberikan oleh industri untuk siswa

4. $\mathrm{C} 4=$ Standar perusahaan, ukuran penilaian standar perusahaan tempat magang bagi mahasiswa

5. $\mathrm{C} 5=$ penerapan $\mathrm{K} 3$ di perusahaan,

6. $\mathrm{C} 6=$ fasilitas dan peralatan praktik untuk peserta magang,

7. $\quad \mathrm{C} 7=$ Bidang keahlian : kesesuaian pekerjaan yang diberikan dengan bidang yang dimiliki oleh mahasiswa

Data kriteria, bobot kriteria beserta normalisasi bobot yang digunakan dapat dilihat pada tabel III. Data kriteria dan bobot yang diberikan bersifat dinamis dimana dapat diubah menyesuaikan dengan kriteria dan point bobot yang diberikan. Dari ketujuh kriteria diberi bobot dan di normalisasi, dimana penjumlahan dari bobot yang dinomalisasi adalah sama dengan 1 sesuai rumus :

$$
W i=\frac{W i^{\prime}}{\Sigma W i^{\prime}}
$$

TABEL III

DATA KRITERIA DAN NORMALISASI BOBOT KRITERIA

\begin{tabular}{|c|c|c|c|}
\hline Kode & Kiteria & Bobot & $\begin{array}{c}\text { Normalisasi } \\
\text { bobot }\end{array}$ \\
\hline $\mathrm{C} 1$ & Jam kerja & $10 \%$ & 0,1 \\
\hline $\mathrm{C} 2$ & $\begin{array}{l}\text { Bobot tugas yang } \\
\text { diberikan selama } \\
\text { magang }\end{array}$ & $10 \%$ & 0,1 \\
\hline $\mathrm{C} 3$ & $\begin{array}{l}\text { Kesesuaian tugas dengan } \\
\text { keahlian }\end{array}$ & $20 \%$ & 0,2 \\
\hline $\mathrm{C} 4$ & Standar perusahaan & $15 \%$ & 0,15 \\
\hline C5 & $\begin{array}{l}\text { Penerapan K3 di } \\
\text { perusahaan }\end{array}$ & $15 \%$ & 0,15 \\
\hline C6 & $\begin{array}{l}\text { Fasilitas dan peralatan } \\
\text { praktik untuk peserta } \\
\text { magang }\end{array}$ & $10 \%$ & 0,1 \\
\hline $\mathrm{C7}$ & Bidang keahlian & $20 \%$ & 0,2 \\
\hline \multicolumn{2}{|r|}{ JUMLAH } & $100 \%$ & 1 \\
\hline
\end{tabular}

2) Penerapan Metode MAUT: Metode MAUT pada sistem aplikasi ini digunakan sebagai bahan pertimbangan, dengan memberikan rekomendasi bagi para mahasiswa yang akan melaksanakan magang dan koordinator sebagai penentu industri tempat magang. Koordinator dapat menolak pengajuan industri tempat magang apabila dalam hasilnya diperoleh bahwa industri tersebut mendapatkan kategori "Tidak Direkomendasikan". Para mahasiswa melakukan magang secara berkelompok, sehingga nantinya dalam perhitungan awal dihitung rata-rata bobot setiap kriteria dari penilaian alternatif industri dilakukan oleh mahasiswa yang telah melaksanakan magang pada industry tersebut. Sebagai data contoh akan disajikan perhitungan terhadap salah satu industry dengan 5 orang mahasiswa.

TABEL IV

PERHITUNGAN AWAL Alternatif BADAN PERTAHANAN NASIONAL (ALTERNATIF A1)

\begin{tabular}{|l|c|c|c|c|c|c|c|}
\hline \multirow{2}{*}{ Responden } & \multicolumn{7}{|c|}{ Kriteria } \\
\cline { 2 - 8 } Nur & 3 & 4 & 3 & 3 & 3 & 4 & 4 \\
\hline $\begin{array}{l}\text { Annisa } \\
\text { Khasanah }\end{array}$ & 3 & 4 & 2 & 4 & 3 & 4 & 2 \\
\hline $\begin{array}{l}\text { Andriana } \\
\text { Oktavia } \\
\text { Kusmawardani }\end{array}$ & 4 & 4 & 3 & 4 & 3 & 4 & 4 \\
\hline $\begin{array}{l}\text { Ria Agustina } \\
\text { Putri }\end{array}$ & 3 & 2 & 2 & 4 & 3 & 3 & 2 \\
\hline $\begin{array}{l}\text { Fadhilah Dhia } \\
\text { Permono }\end{array}$ & 3 & 3 & 4 & 4 & 4 & 3 \\
\hline $\begin{array}{l}\text { Lina } \\
\text { Setyaningsih }\end{array}$ & 3.2 & 3.4 & 2.6 & 3.8 & 3.2 & 3.8 & 3 \\
\hline $\begin{array}{l}\text { Rata2 nilai dari } \\
\text { seluruh } \\
\text { responden }\end{array}$ & & & & & & \\
\hline
\end{tabular}

Dalam prosesnya dilakukan perhitungan terhadap keseluruhan data mahasiswa yang melakukan penilaian terhadap industri sehingga didapatkan nilai rata-rata alternatif dari masing-masing kriteria secara keseluruhan seperti terlihat pada tabel $\mathrm{V}$.

TABEL V

RATING SUB-KRITERIA PADA SETIAP KRITERIA

\begin{tabular}{|c|c|c|c|c|c|c|c|}
\hline Kode & C1 & C2 & C3 & C4 & C5 & C6 & C7 \\
\hline A1 & 3.20 & 3.40 & 2.60 & 3.80 & 3.20 & 3.80 & 3.00 \\
\hline A2 & 3.00 & 2.00 & 2.00 & 3.00 & 2.00 & 3.00 & 2.00 \\
\hline A3 & 3.00 & 4.00 & 3.00 & 3.00 & 4.00 & 3.00 & 3.00 \\
\hline A4 & 3.00 & 3.00 & 2.33 & 3.67 & 3.33 & 3.67 & 3.67 \\
\hline A5 & 3.00 & 3.00 & 2.50 & 3.00 & 4.00 & 3.50 & 2.50 \\
\hline A6 & 2.33 & 3.00 & 2.67 & 3.00 & 3.33 & 2.67 & 3.00 \\
\hline A7 & 3.00 & 3.00 & 4.00 & 3.00 & 3.00 & 4.00 & 4.00 \\
\hline A8 & 3.25 & 3.75 & 3.00 & 4.00 & 3.00 & 3.00 & 3.50 \\
\hline A9 & 3.00 & 2.00 & 2.00 & 3.00 & 3.00 & 2.50 & 2.00 \\
\hline A10 & 3.20 & 3.55 & 3.20 & 3.45 & 3.30 & 3.45 & 3.50 \\
\hline A11 & 3.00 & 3.00 & 3.50 & 3.00 & 3.00 & 3.50 & 3.50 \\
\hline A12 & 3.00 & 3.50 & 3.00 & 3.00 & 3.50 & 3.00 & 3.00 \\
\hline A13 & 3.50 & 4.00 & 3.00 & 3.50 & 3.00 & 4.00 & 3.00 \\
\hline
\end{tabular}

Dari hasil rata-rata diatas, ditentukan terlebih dahulu nilai bobot minimum dan bobot terbaik dari setiap kriteria untuk diolah dalam normalisasi matrix :

$$
U(x)=\frac{x-x i^{-}}{x i^{+}+x i^{-}}
$$

Tahapan selanjutnya dari hasil perhitungan normalisasi matrix akan dikalikan dengan bobot preferensi seperti terlihat dalam tabel VI 
TABEL VI

PERKALIAN MATRIKS DENGAN BOBOT REFERENSI

\begin{tabular}{|c|c|c|}
\hline Alternati & Perhitungan & Hasil \\
\hline A1 & $\begin{array}{l}=(0,74 * 0,1)+(0,7 * 0,1)+(0,3 * 0.2)+ \\
(0,8 * 0.15)+(0,6 * 0,15)+(0,87 * 0,1)+(0,5 * 0,2\end{array}$ & 0.60 \\
\hline $\mathrm{A} 2$ & $\begin{array}{l}=(0,57 * 0,1)+(0 * 0,1)+(0 * 0.2)+ \\
(0 * 0.15)+(0 * 0,15)+(0,33 * 0,1)+(0 * 0,2)\end{array}$ & 0.09 \\
\hline A3 & $\begin{array}{l}=(0,57 * 0,1)+(1 * 0,1)+(0,5 * 0.2)+ \\
(0 * 0.15)+(1 * 0,15)+(0,33 * 0,1)+(0,5 * 0,2)\end{array}$ & 0.54 \\
\hline A4 & $\begin{array}{l}=(0,57 * 0,1)+(0,5 * 0,1)+(0,17 * 0.2)+ \\
(0,67 * 0.15)+(0,67 * 0,15)+(0,78 * 0,1)+(0,83\end{array}$ & 0.58 \\
\hline A5 & $\begin{array}{l}=(0,57 * 0,1)+(0,5 * 0,1)+(0,25 * 0.2)+ \\
(0 * 0.15)+(1 * 0,15)+(0,67 * 0,1)+(0,25 * 0,2)\end{array}$ & 0.42 \\
\hline A6 & $\begin{array}{l}=(0 * 0,1)+(0,5 * 0,1)+(0,33 * 0.2)+ \\
(0 * 0.15)+(0,67 * 0,15)+(0,11 * 0,1)+(0,5 * 0,2)\end{array}$ & 0.33 \\
\hline A7 & $\begin{array}{l}=(0,57 * 0,1)+(0,5 * 0,1)+(1 * 0.2)+ \\
(0 * 0.15)+(0,5 * 0,15)+(1 * 0,1)+(1 * 0,2)\end{array}$ & 0.68 \\
\hline A8 & $\begin{array}{l}=(0,79 * 0,1)+(0,88 * 0,1)+(0,5 * 0.2)+ \\
(1 * 0.15)+(0,5 * 0,15)+(0,33 * 0,1)+(0,75 * 0,2)\end{array}$ & 0.67 \\
\hline A9 & $\begin{array}{l}=(0,57 * 0,1)+(0 * 0,1)+(0 * 0.2)+ \\
(0 * 0.15)+(0,5 * 0,15)+(0 * 0,1)+(0 * 0,2)\end{array}$ & 0.13 \\
\hline A10 & $\begin{array}{l}=(0,74 * 0,1)+\left(0,78^{*} 0,1\right)+(0,6 * 0.2)+ \\
\left(0,45^{*} 0.15\right)+(0,65 * 0,15)+(0,63 * 0,1)+(0,75\end{array}$ & 0.65 \\
\hline A11 & $\begin{array}{l}=(0,57 * 0,1)+(0,5 * 0,1)+(0,75 * 0.2)+ \\
(0 * 0.15)+(0,5 * 0,15)+(0,67 * 0,1)+(0,75 * 0,2)\end{array}$ & 0.55 \\
\hline A12 & $\begin{array}{l}=(0,57 * 0,1)+(0,75 * 0,1)+(0,5 * 0.2)+ \\
(0 * 0.15)+(0,75 * 0,15)+(0,33 * 0,1)+(0,5 * 0,2)\end{array}$ & 0.48 \\
\hline A13 & $\begin{array}{l}=(1 * 0,1)+(1 * 0,1)+(0,5 * 0.2)+ \\
(0,5 * 0.15)+(0,5 * 0,15)+(1 * 0,1)+(0,5 * 0,2)\end{array}$ & 0.65 \\
\hline
\end{tabular}

\section{Implementation}

Tahap ini merupakan tahapan terakhir dalam metode Rapid Application Development.

1. Implementasi hasil dari rancangan antarmuka.

Berikut adalah tampilan dari Sistem Pendukung Keputusan rekomendasi magang industri :

a) Tampilan login

Gambar 7 adalah halaman yang digunakan untuk masuk ke dalam sistem, dengan memasukkan username dan password

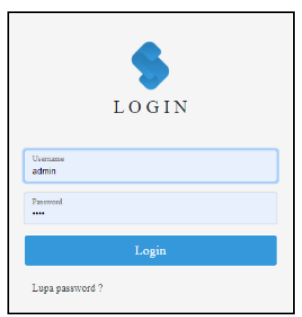

Gambar. 7 Tampilan login system

b) Tampilan tambah kriteria

Dalam halaman tambah kriteria, yang dapat mengubah kriteria adalah admin. Data kriteria terdiri dari nama kriteria, dan bobot. Untuk pengolahan pertama-tama dilakukan proses tambah kriteria terlebih dahulu. Setelah ditambahkan dilakukan normalisasi bobot terhadap semua kriteria yang telah dimasukkan

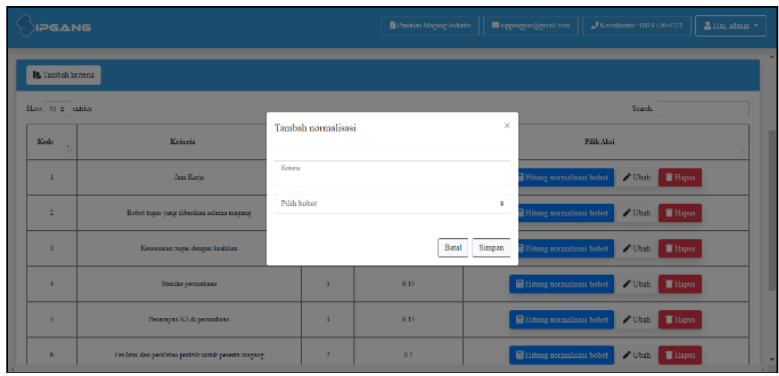

Gambar. 8 Tampilan tambah kriteria

c) Tampilan input nilai kriteria

Halaman input nilai kriteria berisi penilaian yang dilakukan oleh mahasiswa terhadap alternatif industri tempat magang.

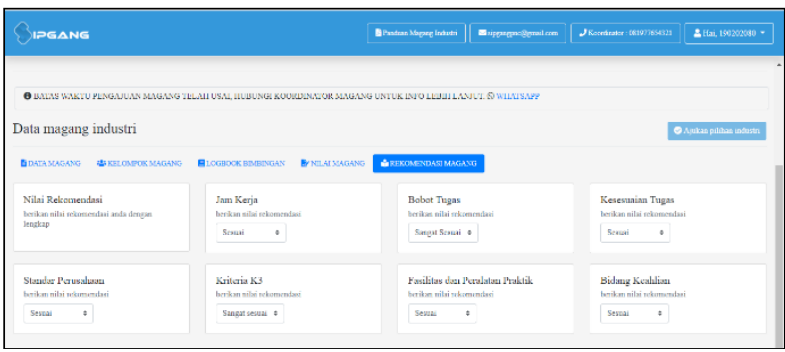

Gambar. 9 Tampilan inputan nilai kriteria

d) Tampilan rata-rata responden

Halaman rata-rata responden berisi tampilan keseluruhan nilai rata-rata dari alternatif industri yang telah dinilai oleh mahasiswa

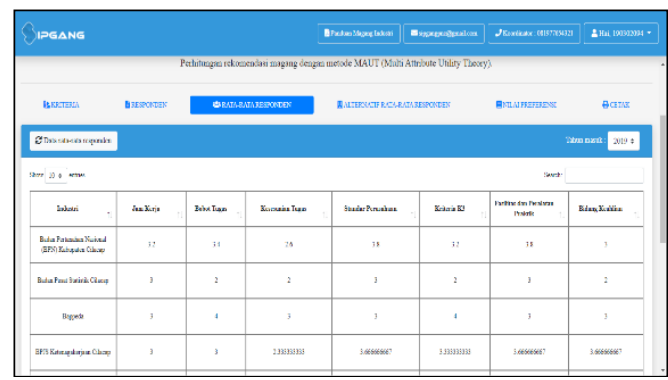

Gambar. 10 Tampilan rata-rata responden

\section{Pengujian Sistem}

Untuk tahapan pengujian sistem menggunakan pengujian validitas perhitungan MAUT dan evaluasi system dengan system usability scale. Pada tahapan pengujian validitas MAUT dilakukan dengan cara membandingkan hasil akhir pada proses manual dengan hasil yang diberikan system. 


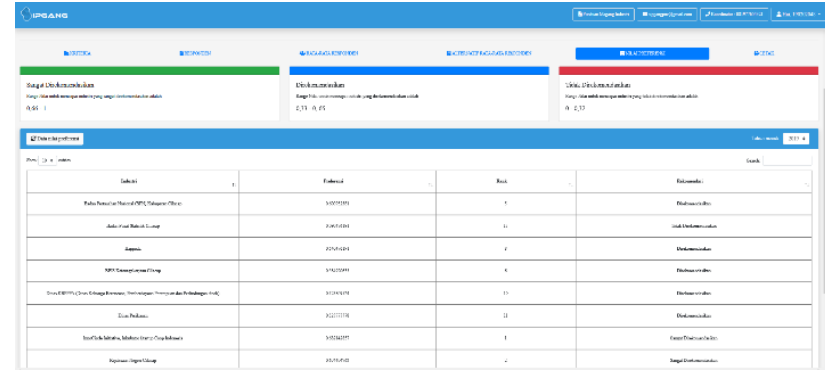

Gambar 11 Hasil nilai preferensi yang diberikan system

Kemudian hasil dari system tersebut disesuaikan dengan perhitungan manual menggunakan Excel seperti tampak pada tabel berikut

TABEL VII

CONTOH PERHITUNGAN BOBOT KRITERIA DARI MASING ALTERNATIF

\begin{tabular}{|c|c|c|c|c|c|c|c|c|}
\hline \multirow[t]{2}{*}{ Alt } & \multicolumn{7}{|c|}{ Kriteria } & \multirow{2}{*}{$\begin{array}{l}\text { Rekom } \\
\text { endasi }\end{array}$} \\
\hline & C1 & C2 & C3 & C4 & C5 & C6 & C7 & \\
\hline A1 & 0.7 & 0.7 & 0.3 & 0.8 & 0.6 & 0.9 & 0.5 & $\begin{array}{l}\text { Sangat } \\
\text { Direkomendas } \\
\text { ikan }\end{array}$ \\
\hline$A 2$ & 0.6 & 0.0 & 0.0 & 0.0 & 0.0 & 0.3 & 0.0 & $\begin{array}{l}\text { Direkomendas } \\
\text { ikan }\end{array}$ \\
\hline A3 & 0.6 & 1.0 & 0.5 & 0.0 & 1.0 & 0.3 & 0.5 & $\begin{array}{l}\text { Direkomendas } \\
\text { ikan }\end{array}$ \\
\hline$A 4$ & 0.6 & 0.5 & 0.2 & 0.7 & 0.7 & 0.8 & 0.8 & $\begin{array}{l}\text { Sangat } \\
\text { Direkomendas } \\
\text { ikan }\end{array}$ \\
\hline A5 & 0.6 & 0.5 & 0.3 & 0.0 & 1.0 & 0.7 & 0.3 & $\begin{array}{l}\text { Direkomendas } \\
\text { ikan }\end{array}$ \\
\hline$A 6$ & 0.0 & 0.5 & 0.3 & 0.0 & 0.7 & 0.1 & 0.5 & $\begin{array}{l}\text { Tidak } \\
\text { Direkomendas } \\
\text { ikan }\end{array}$ \\
\hline A7 & 0.6 & 0.5 & 1.0 & 0.0 & 0.5 & 1.0 & 1.0 & $\begin{array}{l}\text { Sangat } \\
\text { Direkomendas } \\
\text { ikan }\end{array}$ \\
\hline$A 8$ & 0.8 & 0.9 & 0.5 & 1.0 & 0.5 & 0.3 & 0.8 & $\begin{array}{l}\text { Direkomendas } \\
\text { ikan }\end{array}$ \\
\hline A9 & 0.6 & 0.0 & 0.0 & 0.0 & 0.5 & 0.0 & 0.0 & $\begin{array}{l}\text { Tidak } \\
\text { Direkomendas } \\
\text { ikan }\end{array}$ \\
\hline $\begin{array}{l}\text { A1 } \\
0\end{array}$ & $\begin{array}{l}0 . \\
7 \\
\end{array}$ & 0.8 & 0.6 & 0.5 & 0.7 & 0.6 & 0.8 & $\begin{array}{l}\text { Direkomendas } \\
\text { ikan }\end{array}$ \\
\hline $\begin{array}{l}\text { A1 } \\
1 \\
\end{array}$ & $\begin{array}{l}0 . \\
6 \\
\end{array}$ & 0.5 & 0.8 & 0.0 & 0.5 & 0.7 & 0.8 & $\begin{array}{l}\text { Direkomendas } \\
\text { ikan }\end{array}$ \\
\hline $\begin{array}{l}\text { A1 } \\
2 \\
\end{array}$ & $\begin{array}{l}0 . \\
6\end{array}$ & 0.8 & 0.5 & 0.0 & 0.8 & 0.3 & 0.5 & $\begin{array}{l}\text { Direkomendas } \\
\text { ikan }\end{array}$ \\
\hline $\begin{array}{l}\text { A1 } \\
3\end{array}$ & $\begin{array}{l}1 . \\
0\end{array}$ & 1.0 & 0.5 & 0.5 & 0.5 & 1.0 & 0.5 & $\begin{array}{l}\text { Sangat } \\
\text { Direkomendas } \\
\text { ikan }\end{array}$ \\
\hline
\end{tabular}

Dari data yang diberikan diatas dapat diberi kesimpulan bahwa sistem yang dikembangkan telah sesuai, baik dari proses manual maupun hasil yang diberikan oleh sistem

Kemudian setelah pengujian validitas perhitungan akan dilakukan pengujian fungsionalitas dengan menggunakan System Usability Scale. Pengujian ini ditujukan kepada pengguna system agar dapat mengetahui apakah system dapat diterima dan digunakan dengan baik oleh pengguna.
TABEL VIII

LIST PERTANYAAN DALAM SYSTEM USABILITY SCALE

\begin{tabular}{|l|l|}
\hline No. & \multicolumn{1}{|c|}{ Pertanyaan } \\
\hline 1. & $\begin{array}{l}\text { Saya pikir bahwa system ini akan sering saya gunakan } \\
\text { kembali }\end{array}$ \\
\hline 2. & Saya pikir system ini terlalu sulit untuk digunakan \\
\hline 3. & Saya pikir sistemnya mudah dalam penggunaan \\
\hline 4. & $\begin{array}{l}\text { Saya pikir bahwa saya akan membutuhkan bantuan orang lain } \\
\text { agar dapat menggunakan system ini }\end{array}$ \\
\hline 5. & $\begin{array}{l}\text { Saya menemukan fitur - fitur dari system ini yang terintegrasi } \\
\text { dengan baik }\end{array}$ \\
\hline 6. & $\begin{array}{l}\text { Saya pikir ada begitu banyak ketidakkonsistenan dalam } \\
\text { system }\end{array}$ \\
\hline 7. & Saya pikir orang lain cukup memahami system ini \\
\hline 8. & Saya menemukan system ini sangat membingungkan \\
\hline 9. & $\begin{array}{l}\text { Saya merasa tidak ada hambatan dalam menggunakan system } \\
\text { ini }\end{array}$ \\
\hline 10. & $\begin{array}{l}\text { Saya perlu belajar banyak hal sebelum saya bisa melanjutkan } \\
\text { system ini }\end{array}$ \\
\hline
\end{tabular}

Terdapat 10 pertanyaan untuk uji usability dengan 35 responden dimana setiap pertanyaan nomor ganjil maka perhitungannya adalah skor jawaban responden - 1 sedangkan pertanyaan nomor genap maka perhitungannya adalah 5 - skor jawaban reponden. Lalu jumlahkan skor per responden (jumlah skor $\mathrm{x}$ 2.5), jumlahkan dan dibagi dengan responden keseluruhan.

TABEL IX

CONTOH PERHITUNGAN BOBOT

\begin{tabular}{|c|c|c|c|c|c|c|c|c|c|c|c|c|}
\hline \multirow[t]{2}{*}{ No } & \multicolumn{10}{|c|}{ SKOR PERTANYAN } & \multirow[t]{2}{*}{$J M L$} & \multirow{2}{*}{$\begin{array}{l}J M L \\
X 2.5\end{array}$} \\
\hline & 1 & 2 & 3 & 4 & 5 & 6 & 7 & 8 & 9 & 10 & & \\
\hline 1 & 5 & 1 & 5 & 1 & 5 & 1 & 5 & 1 & 5 & 1 & 40 & 100 \\
\hline 2 & 3 & 2 & 4 & 4 & 4 & 2 & 4 & 2 & 4 & 3 & 26 & 65 \\
\hline 3 & 3 & 3 & 2 & 3 & 3 & 2 & 3 & 3 & 1 & 1 & 24 & 60 \\
\hline 4 & 5 & 1 & 5 & 3 & 5 & 2 & 5 & 2 & 5 & 2 & 35 & 88 \\
\hline 5 & 5 & 1 & 5 & 3 & 5 & 2 & 2 & 3 & 3 & 4 & 27 & 68 \\
\hline 6 & 3 & 3 & 3 & 3 & 3 & 3 & 2 & 3 & 3 & 2 & 38 & 95 \\
\hline 7 & 2 & 1 & 5 & 2 & 5 & 1 & 5 & 3 & 5 & 3 & 40 & 100 \\
\hline .. & .. &.. & .. &.. & .. &.. & .. & .. &.. & .. & .. & .. \\
\hline 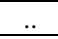 & ... &.. & ... &.. &.. & ... & .. & .. &.. & .. & .. & .. \\
\hline 35 & 4 & 3 & 3 & 4 & 4 & 2 & 3 & 4 & 4 & 4 & 21 & 53 \\
\hline
\end{tabular}

Cara pengukuran usability adalah melalui perhitungan kelayakan yang diperoleh dari skor jawaban dibandingkan dengan skor yang diharapkan seperti terlihat pada rumus berikut:

Prosentase kelayakan $=\frac{\text { skor observasi }}{\text { skor diharapkan }} \times 100 \%$

Berdasarkan rumus tersebut maka :

Skor $_{\text {observasi }}=2510$ (jumlah total seluruh skor usability dari kuisioner)

Skor $_{\text {diharapkan }}=3500$ (skor diharapkan 100 dari 35 responden)

Prosentase kelayakan(\%) $=\frac{2510}{3500} \times 100 \%=72 \%$

Berdasarkan perhitungan dengan SUS diperoleh hasil pada tabel IX kemudian disesuaikan dengan tabel kategori kelayakan berikut, sehingga dapat disimpulkan bahwa dari perhitungan usability menghasilkan nilai prosentase kelayakan 72 yang berarti system yang dikembangkan 
masuk dalam kategori layak (dalam hal usability system) untuk digunakan.

TABEL X

KATEGORI KELAYAKAN

\begin{tabular}{|l|l|}
\hline \multicolumn{1}{|c|}{ Angka } & \multicolumn{1}{c|}{ Kategori } \\
\hline$<21$ & Sangat tidak layak \\
\hline $21-40$ & tidak layak \\
\hline $41-60$ & Cukup \\
\hline $61-80$ & Layak \\
\hline $81-100$ & Sangat Layak \\
\hline
\end{tabular}

\section{E. Hasil Perhitungan Metode MAUT}

Perhitungan kriteria dengan masing-masing bobot menggunakan metode MAUT diperlihatkan pada Tabel XI. Hasil akhir perhitungan tersebut kemudian di beri range sebagai berikut :

TABEL XI

CONTOH PERHITUNGAN BOBOT KRITERIA DARI MASING ALTERNATIF

\begin{tabular}{|l|l|}
\hline \multicolumn{1}{|c|}{ Range Hasil } & \multicolumn{1}{c|}{ Rekomendasi } \\
\hline $0,66-1$ & Sangat Direkomendasikan \\
\hline $0,33-0,65$ & Direkomendasikan \\
\hline $0-0,32$ & Tidak Direkomendasikan \\
\hline
\end{tabular}

Sehingga visualisasi hasil perhitungan rekomendasi dapat dilihat pada Gambar 12

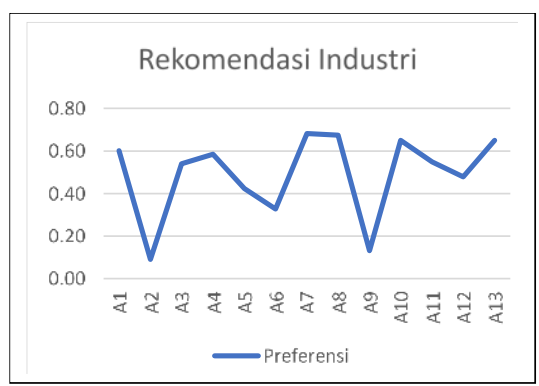

Gambar.12 Grafik visualisasi hasil rekomendasi magang

\section{KESIMPULAN}

Dari hasil penelitian yang dilaksanakan, metode MAUT telah membantu mahasiswa dalam pengambilan keputusan rekomendasi tempat magang berdasarkan kriteria yang telah ditetapkan dan bobot yang dinilai. Dari 13 data alternatif dan dilihat dari grafik visualisasi dapat dilihat terdapat 2 alternatif data industri (A2 dan A9) yang tidak memenuhi kriteria dengan nilai preferensi sebesar 0,09 dan 0,13 . Sistem ini diuji dengan menggunakan Usability Scale dan menghasilkan nilai 72 sehingga dapat disimpulkan bahwa system telah layak digunakan.

\section{REFERENSI}

"Undang-Undang Republik Indonesia No.13 Tahun 2003 tentang Ketenagakerjaan," Undang-Undang, no. 1, pp. 1-34, 2003.

[2] Ismail, Hasan, and Musdalifah, "Pengembangan Kompetensi Mahasiswa Melalui Efektivitas Program Magang Kependidikan," Edumaspul - J. Pendidik., vol. 2, no. 1, pp. 124 132, 2018, doi: 10.33487/edumaspul.v2i1.48.

[3] U. Verawadina, N. Jalinus, and L. Asnur, "Kurikulum Pendidikan Vokasi Pada Era Revolusi Industri 4.0," J. Pendidik., vol. 20, no. 1, pp. 82-90, 2019, doi: 10.33830/jp.v20i1.843.2019.

Muslih, "Analisis Efektifitas Program Magang Untuk Sinkronisasi Link and Match Perguruan Tinggi dengan Dunia Industri," J. Manaj. Bisnis, vol. 14, no. 01, pp. 64-76, 2014.

[5] D. Aldo, N. Putra, and Z. Munir, "Sistem Pendukung Keputusan Penilaian Kinerja Dosen Dengan Menggunakan Metode Multi Attribute Utility Theory ( Maut),"Jursima (Jurnal Sist. Inf. dan Manajemen), vol. 7, no. 2, pp. 16-22, 2019, doi: 10.47024/js.v7i2.180.

[6] D. Winarso, F. Nurita, and S. Syahril, "Penerapan Metode Weigth Product Untuk Rekomendasi Penempatan Praktek Kerja Industri (Study Kasus: SMK Muhammadiyah 01 Pekanbaru),' J. RESTI (Rekayasa Sist. dan Teknol. Informasi), vol. 2, no. 2 , pp. 566-571, 2018, doi: 10.29207/resti.v2i2.467.

[7] Y. H. Agustin, S. S. Sundari, and Y. Y. Dewi, "Alternative (DIA) Untuk Rekomendasi Tempat Prakerin di SMKN Bantarkalong," Semin. Nas. Sist. Inf. dan Tek. Inform., pp. 127-136, 2019.

[8] I. P. Luis Rusdiyanto, R. Latuconsina, and R. Wijaya, "Sistem Pendukung Keputusan Terhadap Rekomendasi Perusahaan Tempat Kerja Praktik Bagi Mahasiswa FTE Universitas Telkom Menggunakan Naive Bayes," e-Proceeding Eng., vol. 7, no. 2, pp. 4968-4975, 2020.

[9] S. Aswati, M. S. Ramadhan, A. U. Firmansyah, and K. Anwar "Studi Analisis Model Rapid Application Development Dalam Pengembangan Sistem Informasi," J. Matrik, vol. 16, no. 2, p. 20, 2017, doi: 10.30812/matrik.v16i2.10.

[10] M. Prabowo and A. Suprapto, "Implementasi Metode Profile Matching Dalam Aplikasi Penerimaan Siswa Baru pada SMK Ma'arif NU 2 Boyolali," Jusifo, vol. 5, no. 2, pp. 71-80, 2019, doi: 10.19109/jusifo.v5i2.5189.

[11] M. P. Putri and H. Effendi, "Implementasi Metode Rapid Application Development Pada Website Service Guide 'Waterfall Tour South Sumatera,'” J. SISFOKOM, vol. 07, no. September, pp. 130-136, 2018.

[12] R. Schäfer, "Rules for using multi-attribute utility theory for estimating a user's interests," Evaluation, pp. 1-7, 2001.

[13] M. Anranur Uwaisy, Z. K. A. Baizal, and M. Yusza Reditya, "Recommendation of scheduling tourism routes using tabu search method (case study bandung)," Procedia Comput. Sci. vol. 157, pp. 150-159, 2019, doi: 10.1016/j.procs.2019.08.152.

[14] J. C. Chacon-Hurtado and L. Scholten, "Decisi-o-rama: An open-source Python library for multi-attribute value/utility decision analysis," Environ. Model. Softw., vol. 135, no. September 2020, p. 104890, 2021, doi: 10.1016/j.envsoft.2020.104890.

[15] M. Hidayat, P. A. Jusia, and Amroni, "Analisa dan Perancangan Sistem Pendukung Keputusan Untuk Penerimaan Karyawan PT Dos Ni Roha Jambi Menggunakan Metode MAUT (Multi Attribute Utility Theory)," J. Process., vol. 13, no. 1, 2018.

[16] J. Nasution and M. Syahrizal, "Sistem Pendukung Keputusan Rekomendasi Calon Kepala Puskesmas Mengunakan Metode Multi Attribute Utility Theory (Maut) (Studi Kasus: Puskesmas Desa Lama Sei Lepan)," KOMIK (Konferensi Nas. Teknol. Inf. dan Komputer), vol. 3, no. 1, pp. 176-182, 2019, doi: 10.30865/komik.v3i1.1586. 